\title{
DETERMINATION OF KINETICS IN GAS-LIQUID REACTION SYSTEMS. AN OVERVIEW
}

\author{
PRZEGLĄD METOD WYZNACZANIA KINETYKI REAKCJI GAZ-CIECZ
}

\begin{abstract}
The aim of this paper is to present a brief review of the determination methods of reaction kinetics in gas-liquid systems with a special emphasis on $\mathrm{CO}_{2}$ absorption in aqueous alkanolamine solutions. Both homogenous and heterogeneous experimental techniques are described with the corresponding theoretical background needed for the interpretation of the results. The case of $\mathrm{CO}_{2}$ reaction in aqueous solutions of methyldiethanolamine is discussed as an illustrative example. It was demonstrated that various measurement techniques and methods of analyzing the experimental data can result in different expressions for the kinetic rate constants.
\end{abstract}

Keywords: gas-liquid reaction kinetics, stirred cell, stopped-flow technique, enhancement factor, $\mathrm{CO}_{2}$ absorption, methyldiethanolamine

\section{Introduction}

Multiphase reaction systems are frequently encountered in chemical reaction engineering practice. Typical examples of industrially important processes where these systems are found include gas purification, oxidation, chlorination, hydrogenation and hydroformylation processes. Among them, the $\mathrm{CO}_{2}$ removal by aqueous solutions of amines received considerable attention. Since $\mathrm{CO}_{2}$ is regarded as a major greenhouse gas, potentially contributing to global warming, there has been substantial interest in developing amine-based technologies for capturing large quantities of $\mathrm{CO}_{2}$ produced from fossil fuel power plants. Absorption of $\mathrm{CO}_{2}$ by chemical solvents is the most popular and effective method which can be implemented in this sector. Industrially important alkanolamines for $\mathrm{CO}_{2}$ removal are the primary amine monoethanolamine (MEA), the secondary amine diethanolamine (DEA) and diisopropanolamine (DIPA) and the tertiary amine methyldiethanolamine (MDEA) and triethanolamine (TEA) [1]. The $\mathrm{CO}_{2}$ reaction with alkanolamines is of wide importance and its kinetics is crucial for complete modeling of the absorption process. An inaccurate estimation of the kinetics of gas-liquid reactions may lead to an erroneous design of absorption equipment, since the accuracy of process modeling

\footnotetext{
${ }^{1}$ Faculty of Process and Environmental Engineering, Technical University of Lodz, ul. Wólczańska 213, 90-924 Łódź, Poland, phone: +48 4263137 74, fax +48 426365663

*Corresponding author: kierzkow@p.lodz.pl
} 
strongly depends on the quality of the model parameters. Besides the kinetics data, the model parameters include many physical properties such as density, viscosity, solubility, and diffusivity of a gas component in a particular solution.

A large amount of literature on the determination of the kinetics of gas-liquid reactions is available. Several different types of equipment were developed to measure the rate of gas-liquid reactions. The most important ones include the laminar jet, wetted wall apparatus of different construction and a stirred cell [2]. In principle, the mass transfer area and the physical mass transfer coefficients must be known in these units and the effect of the chemical reaction may be then separated from the diffusional mass transfer. A brief review of the theory and experimental methods for studying gas-liquid reaction kinetics is given in a recent article of Vaidya and Kenig [3]. The authors stress that due to the diversity of measurement techniques and different theoretical models used for the interpretation of data, the obtained results may be erroneous. Even for identical experimental conditions, significant deviations in the estimated kinetic parameters may arise in different investigations.

The similar conclusion was earlier made by Aboudheir et al [4] who reviewed the literature data on the kinetics of $\mathrm{CO}_{2}$ reaction with aqueous MEA and revealed large discrepancies between the values or expressions of the reported second order reaction rate constants. The wide variation that has been found in the values of reaction rate constant was attributed to uncertainties in the physical properties used, inability to determine the exact contact area between a gas and liquid in the absorption process, the possibility of existence of interfacial turbulence in some types of absorbers, and the assumption of a pseudo first order reaction.

The aim of this paper is to present a brief review of the determination methods of reaction kinetics in gas-liquid systems with a special emphasis on $\mathrm{CO}_{2}$ absorption in aqueous alkanolamine solutions. Both homogenous and heterogeneous experimental techniques will be described with the corresponding theoretical background needed for the interpretation of results. The selected approximate methods for the data analysis will be discussed. A concise description of the operation of a stirred-cell and a conductometric stopped-flow apparatus is outlined. The case of $\mathrm{CO}_{2}$ reaction in aqueous solutions of MDEA is discussed as an illustrative example of the use of both techniques for determination of kinetics. It will be demonstrated that different experimental techniques and methods of analyzing the experimental data can substantially influence the resulting expressions for the kinetic constants.

\section{The concept of enhancement factor in mass transfer with chemical reaction}

In the past, several theoretical approaches to the description of mass transfer in gas-liquid systems have been proposed, including models based on the film theory and models based on the penetration and surface renewal theories which are based on non-stationary description of the process. Among them, the film model is the most often applied [5] as it is mathematically simpler than the penetration-type models. According to the film theory, mass transfer takes place by molecular diffusion through a stagnant liquid/gas layer of thickness $\delta$, while the bulk of liquid/gas is well mixed. Typical 
concentration profiles of components for the general case of absorption with chemical reaction are illustrated in Figure 1.

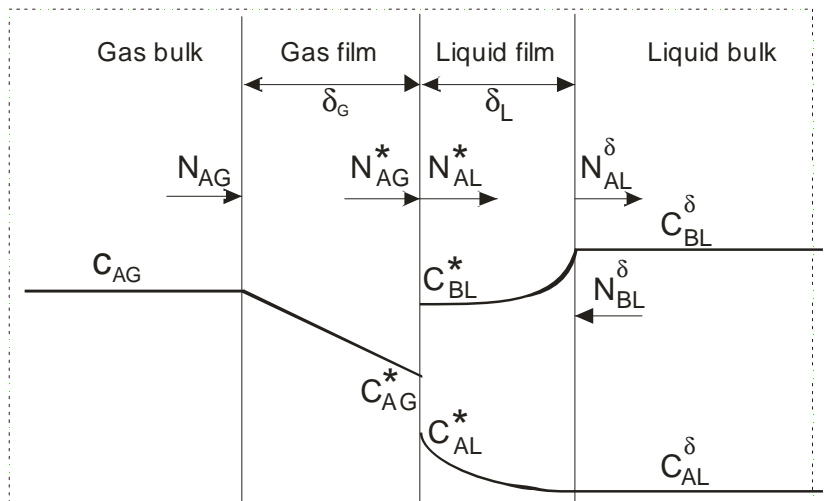

Fig. 1. Concentration profiles of components for the general case of absorption with chemical reaction (film theory)

Generally, the absorption rate of $\mathrm{CO}_{2}$ into an amine solution in the absence of gas-phase limitation is often represented by the following simple equation:

$$
N_{A L}^{*}=E_{A} k_{A L}\left(c_{A L}^{*}-c_{A L}^{\delta}\right)
$$

where $N_{A L}^{*}$ is the flux entering the liquid phase, $k_{A L}$ is the mass transfer coefficient of $\mathrm{CO}_{2}$ in the liquid phase, $c_{A L}^{*}$ and $c_{A L}^{\delta}$ are the interfacial and bulk $\mathrm{CO}_{2}$ concentrations, respectively. The enhancement factor $E_{A}$ describes the influence of a chemical reaction on the mass transfer rate. This factor is defined as the ratio of the absorption rate of a gas component in the liquid in the presence of a chemical reaction to the absorption rate in the absence of a reaction at identical concentration driving force. The advantage of this definition is that all the effects of chemical reaction on the absorption rate are incorporated in this single factor. However, there is no a general analytical expression to calculate this value. The exact determination of enhancement factor requires the solution of a set of differential equations that govern the simultaneous diffusional mass transfer and chemical reactions.

A number of different methods for the description of the enhancement factor can be found in the literature. Analytical expressions for the enhancement factor based on the film model are restricted to some asymptotic cases of absorption with chemical reaction in which simplified assumptions about the reaction regime are made. Moreover, they are related to the specific cases with zero gas concentration in the liquid bulk $\left(c_{A L}^{\delta}=0\right)$ and hence Eq. (1) can be simplified to:

$$
N_{A L}^{*}=E_{A} k_{A L} c_{A L}^{*}
$$

For the majority of processes in which mass transfer is followed by chemical reactions it is not possible to present analytically derived expressions for the calculation of enhancement factor that are valid over a wide range of process conditions. As already 
mentioned, besides numerically derived solutions, an alternative approach is the calculation of the mass transfer rate via the enhancement factor, by means of approximated methods for the description of the given absorption case. A number of different methods for the approximate calculation of enhancement factors are overviewed by van Swaaij and Versteeg [6].

\section{Kinetics of a second order chemical reaction}

Let us consider a second order, irreversible chemical reaction between the dissolved gas component $\mathrm{A}\left(\mathrm{CO}_{2}\right)$ and a non-volatile liquid component $\mathrm{B}$ (amine) that proceeds according to the following stoichometry:

$$
A(g)+v_{B} B(l) \stackrel{k_{2}}{\longrightarrow} \operatorname{Products}(l)
$$

The enhancement factor is a function of two parameters, the Hatta number and the enhancement factor of an infinitely fast reaction. The Hatta number is defined as the ratio of the maximum amount of consumed component in the liquid film and the maximum amount transferred if no chemical reaction occurs and at zero bulk concentration. This number is given by:

$$
\mathrm{Ha}=\frac{\sqrt{k_{2} D_{A L} c_{B L}^{\delta}}}{k_{A L}}
$$

The Hatta number is actually the criterion for whether the reaction occurs completely in the liquid bulk or completely in the liquid film. The infinite enhancement factor $E_{\text {inf }}$ is dependent on the choice of a mass transfer model and for a film theory it is expressed by:

$$
E_{\mathrm{inf}}=1+\frac{D_{B L} c_{B L}^{\delta}}{v_{B} D_{A L} c_{A L}^{*}}
$$

Generally, at increasing values of the Hatta number the chemical reaction is approaching the gas-liquid interface and the enhancement factor $E_{A}$ is limited by the value given by $E_{\text {inf }}$. Depending on the absolute value of Hatta number and the ratio between $\mathrm{Ha}$ and $E_{\text {inf }}$ three absorption regimes can occur. For the experiments carried out at a constant amine concentration and at given hydrodynamic conditions characterized by a certain $k_{A L}$, changing the gas partial pressure may affect the impact of a chemical reaction on the $\mathrm{CO}_{2}$ absorption rate.

a) Fast pseudo first order regime. In the fast pseudo first order regime the ratio of the Hatta number and the $E_{\text {inf }}$ is sufficiently large. The pseudo first order conditions are possible when amine is present in excess in comparison to $\mathrm{CO}_{2}$. In this case the concentration of amine in the liquid film is almost constant and the same as that in the liquid bulk as depicted in Figure 2. If the following condition is fulfilled:

$$
2<\mathrm{Ha}<<E_{\text {inf }}
$$

then $c_{B L}^{*} \cong c_{B L}^{\delta}$ and the enhancement factor $E_{A}$ can be analytically derived as follows:

$$
E_{A}=\frac{\mathrm{Ha}}{\tanh (\mathrm{Ha})}
$$

The interfacial concentration of $\mathrm{CO}_{2}$ is typically related to $\mathrm{CO}_{2}$ partial pressure through Henry's law according to: 


$$
c_{A L}^{*}=\frac{p_{A}}{\mathrm{He}}
$$

Taking into account that for $\mathrm{Ha}>3, \tanh \mathrm{Ha} \cong \mathrm{Ha}$ and introducing Eq. (8) into Eq. (2) gives:

$$
N_{A L}^{*}=\frac{\sqrt{k_{o v} D_{A L}} p_{A}}{\mathrm{He}}
$$

where $k_{o v}$ is the overall reaction rate constant defined as:

$$
k_{o v}=k_{2} c_{B L}^{\delta}
$$
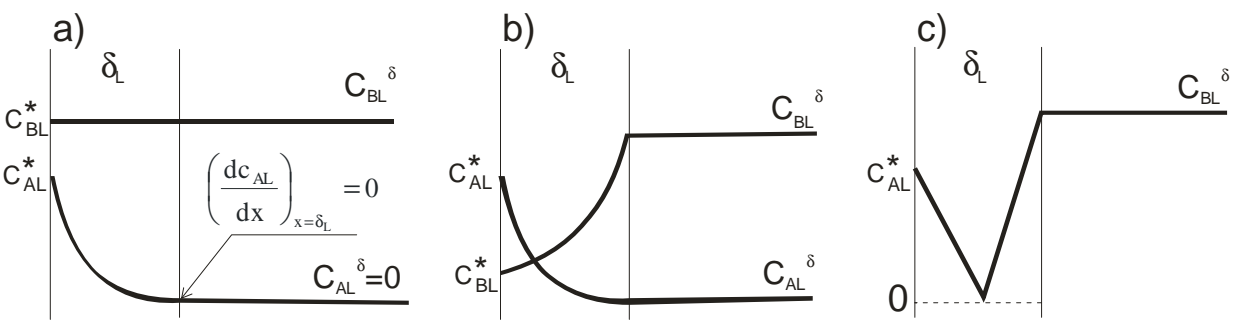

Fig. 2. Concentration profiles of components for three cases of absorption with chemical reaction: a) fast pseudo first order regime, b) intermediate regime, c) instantaneous reaction in the liquid film

Upon satisfaction of Eq. (6) the reaction of $\mathrm{CO}_{2}$ with the amine can be considered to take place in the fast pseudo first order regime which means that the reaction is of the first order with respect to $\mathrm{CO}_{2}$ and the concentration of free amine does not change much throughout the reaction zone. From Eq. (9) it can be seen that the experimentally observed absorption rate can give direct information on the kinetic rate constant $k_{o v}$ supposing that values of $\mathrm{He}$ and $D_{A L}$ for $\mathrm{CO}_{2}$ in amine solution are known. It also obvious from Eq. (9), that in the pseudo first order chemical absorption regime, the absorption rate is independent of the hydrodynamic conditions expressed by liquid side mass transfer coefficient $k_{A L}$. The sensitivity of the measured absorption rate to the rate of chemical reaction is at the maximum with $N_{A L}^{*} \sim k_{2}^{0.5}$. This defines the ultimate condition for the measurement of rate constants in $\mathrm{CO}_{2}$ /alkanoamine systems [9]. It may be noted, that different criteria have been reported in the literature for this case to specify conditions under which the reaction of $\mathrm{CO}_{2}$ with the alkanolamines can be safely considered to take place in the pseudo first order regime [3]. The analysis regarding a priori restriction on the reaction regime should by thus performed very carefully as it determines the selection of the applicable expression for an enhancement factor.

b) Fast intermediate regime. While increasing $\mathrm{CO}_{2}$ partial pressure (and hence increasing the $\mathrm{CO}_{2}$ concentration at the interface), the value of the infinite enhancement factor decreases and depletion of the amine at the interface starts to occur. In this intermediate regime, it is not possible to derive the kinetic rate constant directly from the measured $\mathrm{CO}_{2}$ absorption rates according to Eq. (9). However, numerous approximate solutions for the enhancement factor as a function of both the Hatta number and the infinite enhancement factor are available in the literature that are applicable over a wide range of 
process conditions. In the present work, an explicit approximate solution of Wellek based on film theory and developed for an irreversible second order chemical reaction, is used to interpret experimental data [5]:

$$
E_{A}=1+\frac{1}{\left[\left(E_{\mathrm{inf}}-1\right)^{-1.35}+\left(\frac{\mathrm{Ha}}{\tanh \mathrm{Ha}}-1\right)^{-1.35}\right]^{1 / 1.35}}
$$

The use of Eq. (11) to derive kinetics requires experimental determination of the enhancement factor and knowledge of several physicochemical parameters which are involved in $\mathrm{Ha}$ and $E_{\text {inf. }}$. The reaction rate constant is calculated by using the Hatta number as a fitting parameter so that the enhancement factor calculated using Eq. (11) matches the experimentally observed enhancement factor [7].

c) Instantaneous regime. On further increase of $\mathrm{CO}_{2}$ partial pressure, the infinite enhancement factor becomes smaller than the Hatta number. In the instantaneous regime, the following condition is satisfied:

$$
2<E_{\text {inf }}<<\mathrm{Ha}
$$

In this region, the rate of chemical reaction is instantaneous with respect to mass transfer and the rate of absorption is completely limited by diffusion of the reactants. A reaction plane is formed at some distance from the gas-liquid interface (Fig. 2c). In this case the diffusion of reactants to this plane determines the mass transfer rate. Therefore the determination of kinetics from the experimental data is impossible. In this regime, the maximum enhancement factor applies and the $\mathrm{CO}_{2}$ absorption rate is:

$$
N_{A L}^{*}=E_{\text {inf }} k_{A L} c_{A L}^{*}
$$

The above discussion on the reaction regimes serve to underline the importance of proper planning the kinetic experiments for unknown systems. Since the kinetics of a given $\mathrm{CO}_{2}$-amine system is not known prior to the research, it is not possible to determine beforehand in which regime the experiments are carried out. Therefore, at a constant Hatta number maintained by fixed temperature, the amine concentration and hydrodynamics of a liquid phase, a series of absorption experiments should be realized with decreasing the $\mathrm{CO}_{2}$ partial pressure. While reaching a pseudo first order regime, a linear relationship between the experimental $\mathrm{CO}_{2}$ absorption rate and the $\mathrm{CO}_{2}$ partial pressure should be found. According to Eq. (9), the kinetic rate constant can be directly extracted from the slope of the relation between the $\mathrm{CO}_{2}$ absorption rate and its partial pressure.

It should be stressed that Eq. (9) was derived only for an irreversible reaction. Thus, for a reliable determination of the rate constant in the fast, pseudo first order regime, the experiments should be carried out with unloaded solutions. Hence, the absorption rate is not affected by the reverse reaction because the product concentration remains negligible.

As already stated above, for the estimation of kinetic rate constants, several physical parameters must be known. The physical solubility, diffusion coefficient and mass transfer coefficient of $\mathrm{CO}_{2}$ in aqueous amine solution cannot be measured directly. Therefore, these parameters can be estimated by means of an inert gas which is similar to $\mathrm{CO}_{2}$. In view of the similarities with regard to configuration, molecular volume and electronic structure, $\mathrm{N}_{2} \mathrm{O}$ is often used as a non-reacting gas to estimate the properties of $\mathrm{CO}_{2}[8,9]$. For example, the 
solubility of $\mathrm{CO}_{2}$ in reactive alkanolamines solutions can be estimated by measuring the corresponding data of $\mathrm{N}_{2} \mathrm{O}$ and multiplying it by the ratio of the solubility of $\mathrm{CO}_{2}$ to that of $\mathrm{N}_{2} \mathrm{O}$ in water. It should be noted that uncertainties in solubility or diffusivity data can lead to errors in the estimation of reaction kinetics.

\section{Heterogeneous techniques}

The large number of gas-liquid laboratory apparatus to obtain accurate kinetic rate data is available. In this equipment the hydrodynamics, mass-transfer resistances and the interfacial area should be well defined. The most important ones including a laminar jet, the wetted wall column, the wetted sphere absorber and a stirred cell are illustrated in Figure 3 [3]. The gas-liquid interfacial area is indicated by the arrow with "G-L" notation. Typical values of the liquid phase mass transfer coefficients and contact times are presented in Table 1. Measurements of the kinetics of gas-liquid reactions should be carried out at relatively high mass transfer coefficients because the higher the value of this coefficient, the smaller the impact of diffusion phenomena on the mass transfer rate.

Table 1

Characteristics of experimental apparatus used for gas-liquid reactions

\begin{tabular}{|c|c|c|}
\hline Apparatus & Contact time [s] & $\boldsymbol{k}_{\boldsymbol{A L}} \cdot \mathbf{1 0} \mathbf{3}[\mathbf{m} / \mathbf{s}]$ \\
\hline Laminar jet & $0.01 \div 0.1$ & $0.16 \div 1.6$ \\
Wetted wall column & $0.1 \div 2$ & $0.036 \div 0.16$ \\
Wetted sphere absorber & $0.1 \div 1$ & $0.05 \div 0.16$ \\
Stirred cell & $>1$ & $0.016 \div 0.1$ \\
\hline
\end{tabular}

The gas-liquid interfacial area and gas-liquid mass transfer coefficient can be widely varied and estimated accurately in a laminar jet. According to Shah [2], it is the most flexible laboratory absorber. By varying jet length and the liquid flow rate, both the interfacial area and $k_{A L}$ can be changed. In other apparatus, the interfacial area is mainly limited by dimensions of a given equipment size. The advantage of knowing the interfacial area and mass transfer coefficient in advance is that the reaction kinetics and mass transfer can be decoupled and the measured rate data can be easily interpreted to study the kinetics of gas-liquid reactions [10]. Among commonly used absorbers, the stirred cell reactor is widely applied because of its simplicity of construction and operation. This reactor can be operated under strict isothermal conditions and can also be applied to determine gas solubility in a liquid. It can also be used in gas-liquid-solid reactions, where the solid is a reactant. A considerable amount of kinetic studies is available in the literature with the use of this apparatus [3, 11-15].

A typical reactor of that type is a cylindrical vessel with a stirring device. This type of vessel is classified as a stirred tank or well mixed reactor as the composition and temperature of the reaction is homogenous in all parts of the vessel. The vessel contains internals such as baffles, feed and drain pipes and probes (eg thermocouples, pressure transducers). The degree of mixing and power requirement depends on the nature of the internals present in the vessel and the type and position of the stirrer [2]. The reactor lid holds the shaft seal and the necessary armature for charging and sampling both from the gas and liquid phases. For an axially positioned stirrer, agitation causes rotational motion of the liquid and vortex formation. The bulk rotation of the liquid is generally prevented by the 
installed baffles, which are usually attached to the vessel wall by means of welded brackets. Stirring devices are subject to mechanical and sealing difficulties especially in pressurized operations. In order to prevent gas leakage, the stirrer is often placed in the bottom of the reactor. Significant progress was made in recent years in a stirrer construction by introducing magnetically coupled stirrer drives thereby avoiding the leakage problems. The most common type of stirrer is the turbine type with four or six blades on a disk and an impeller stirrer. In certain types of stirred cell reactors, both the gas and liquid phases are agitated by two stirrers which are mounted on the same shaft.

Thermal effects occurring during the gas-liquid reaction arise from phase changes accompanying a gas absorption and chemical reaction occurring in the liquid phase. Possible temperature increase due to aforementioned heat effects can increase a mass transfer rate due to an increase in mass transfer coefficients and decrease it due to a decrease in solubility of the absorbed gas. As the chemical reaction rate is very sensitive to temperature, maintaining the constant temperature during a measurement is a very important issue. The cooling and heating in a stirred vessel is achieved in a number of different ways. The most conventional method is the use of thermostating liquid bath where the reactor is submerged while in use. Another method involves the heat transfer through the circulated water in the jacketed reactor. Additionally, a Peltier element mounted inside the bottom of the reactor can serve as an efficient heating and cooling device [15].
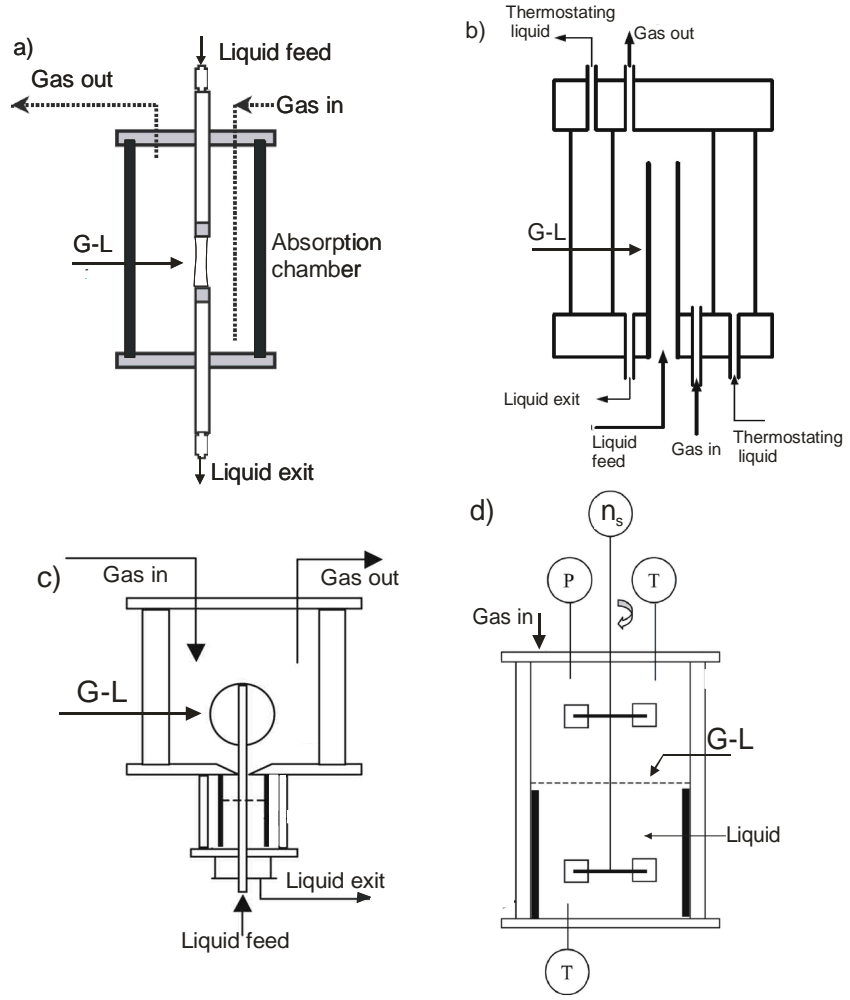

Fig. 3. Typical absorption apparatus: a) laminar jet, b) wetted wall column, c) wetted sphere absorber, d) stirred cell (modified from Ref. [3]) 
The hydrodynamics of the stirred cell reactor is often described by means of a power law relationship of dimensionless numbers:

$$
\mathrm{Sh}=A_{1} \operatorname{Re}^{a} \mathrm{Sc}^{b}
$$

The Sherwood, Reynolds and Schmidt numbers are defined as:

$$
\begin{gathered}
\mathrm{Sh}=\frac{k_{A L} d_{s}}{D_{A L}} \\
\operatorname{Re}=\frac{n_{s} d_{s}^{2} \rho_{L}}{\eta_{L}} \\
\mathrm{Sc}=\frac{\eta_{L}}{\rho_{L} D_{A L}}
\end{gathered}
$$

where $d_{s}$ and $n_{s}$ are the dimension and the speed of the stirrer, respectively. The values of $b$ were reported to range from 0.33 for small Sc numbers to 0.5 for large Sc numbers. The exponent of power dependence of the Sh number on Re number is found to be in the range $0.6 \div 0.7$ [16]. The mass transfer characteristics described by Eq. (14) is typically determined by measuring physical mass transfer coefficients for $\mathrm{CO}_{2}$ in water and $\mathrm{N}_{2} \mathrm{O}$ in aqueous amine solutions under various operating conditions. From Eq. (14) which is based on the results of the physical absorption measurements, the values of physical mass transfer coefficient for reacting systems can be calculated as they are very important for the identification a chemical absorption regime and interpretation of the experimental data.

The experiments in the stirred cell are typically conducted in the range of stirring speed of $50 \div 180 \mathrm{~min}^{-1}$ to maintain the gas-liquid interface flat and smoothed. The typical values of $k_{A L}$ in this range are reported in Table 1. It should be noted that for well defined gas-liquid contact area, the liquid mass transfer coefficient is relatively low in the stirred cell which limits its applicability for fast reactions.

\section{Experimental procedure in a stirred cell}

Stirred cell reactors can be operated batchwise with respect to the liquid phase. Regarding the gas phase, the experiments are performed in a batchwise or semi-batchwise mode. In full batch experiments, the absorption process is monitored by recording the pressure decrease in the reactor versus time. At the beginning of the experiment, the gas is introduced into the reactor in a very short time while the liquid is first loaded, degassed and thermostated at desired temperature. Switching of the stirrer initiates the absorption process and causes pressure decrease. This way of realizing the absorption process aimed at determining the reaction kinetics is described in detail in the previous paper [15]. The $\mathrm{CO}_{2}$ absorption rate can be calculated from the experimental data by the mass balance in the reactor gas phase according to:

$$
-\frac{V_{G}}{R \cdot T \cdot A} \frac{\mathrm{d} p_{A}}{\mathrm{~d} t}=N_{A L}^{*}
$$

where $V_{G}$ is the gas phase volume in the reactor, $T$ is the temperature, $R$ is the gas constant and $A$ is the gas-liquid interfacial area. In Eq. (18), the ideal gas phase behavior was applied. Typically, at partial pressures close to atmospheric pressure, the application of the 
ideal gas law does not cause significant errors relative to the real gas equations. In a semibatch mode, the pressure in the reactor is kept constant using a back pressure regulator and the gas is continuously fed to the reactor from a calibrated gas storage vessel of a known volume. In this case, the absorption rate can be determined from the pressure decrease in the gas reservoir or it can be directly measured by a mass flow meter mounted on a gas feed line between the gas reservoir and reactor. This type of operation is preferred over a batchwise mode with respect to the gas phase in view of experimental accuracy in the case when the pseudo first-order criteria indicated the requirement of a relatively low $\mathrm{CO}_{2}$ partial pressure in the reactor. During a batchwise mode and the occurrence of a fast reaction, this would directly imply a relatively high pressure decrease (from an already low initial pressure) over a short period. A semi-batchwise operation takes a longer experimental time in the desired pseudo first order regime, thereby improving the experimental accuracy [17]. A typical experimental set-up with stirred cell apparatus and both methods of conducting experiments with respect to the gas phase are illustrated in Figures 4 and 5.

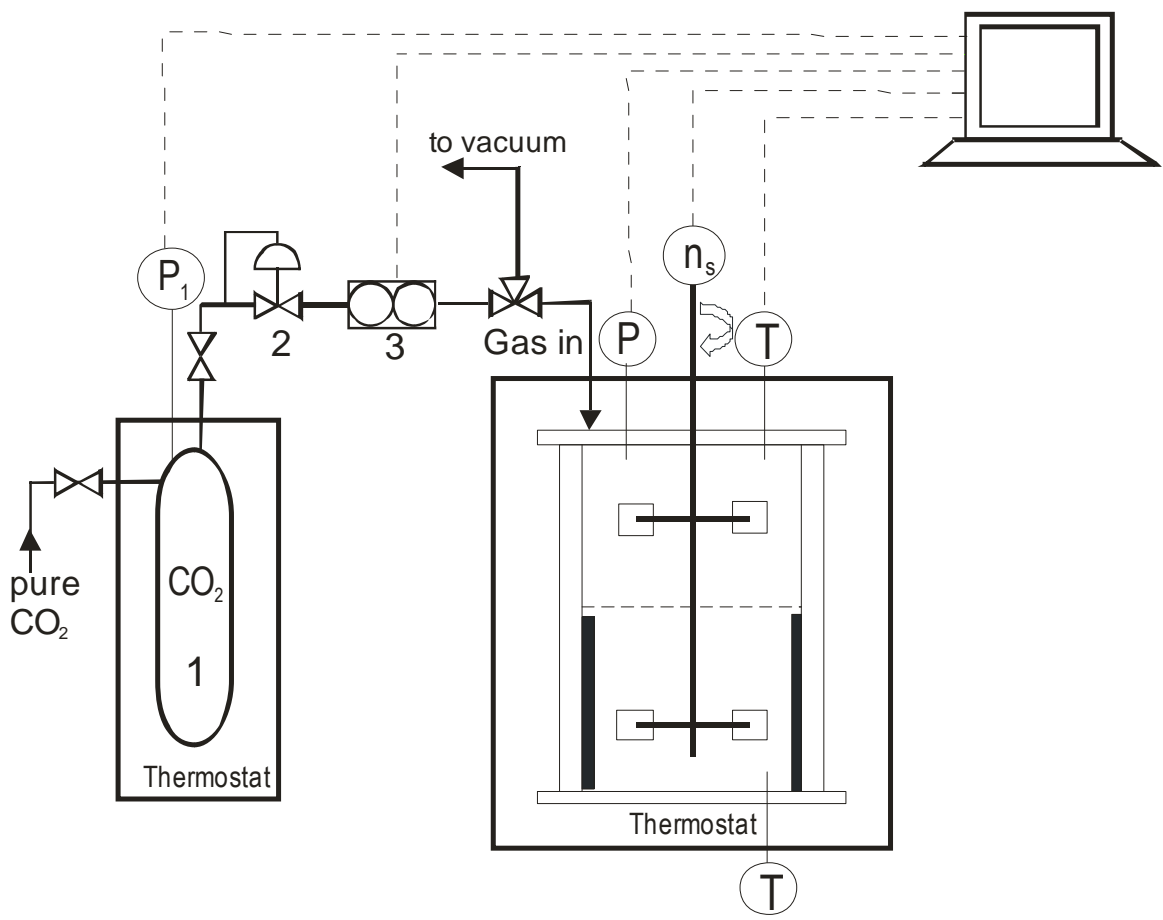

Fig. 4. Set-up with a stirred cell apparatus suited for batchwise and semi-batchwise mode of operation with respect to the gas phase: 1 - gas storage vessel, 2 - back pressure regulator, 3 - mass flow meter

Irrespective of the method of conducting the absorption experiments and corresponding way of calculating of the $\mathrm{CO}_{2}$ absorption rate, Eq. (9) can be applied to determine gas-liquid reaction kinetics if the pseudo first order criteria is fulfilled. 
a)

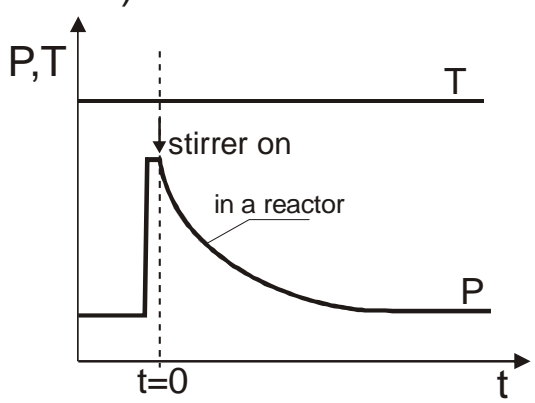

b)

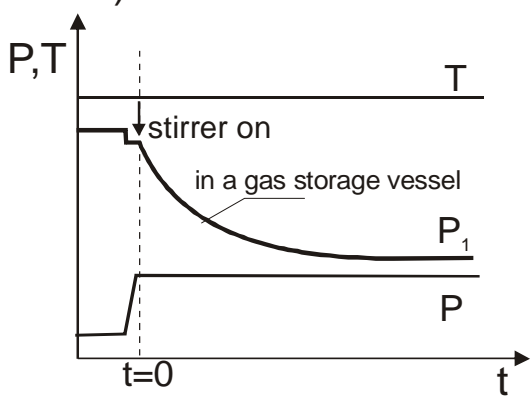

Fig. 5. Experimental procedure for a) batchwise, b) semi-batchwise mode of operation with respect to the gas phase

\section{Homogenous techniques}

In order to avoid the uncertainty associated with the measurement of several physical properties such as diffusivity and gas solubility in the liquid phase, homogeneous experimental techniques are also used to study gas-liquid reaction kinetics. Stopped-flow method is one of the most frequently used homogenous techniques suited for monitoring fast reaction kinetics taking place in the liquid phase. In this method there is no mass transfer resistance associated with the transfer of a gas component into the liquid phase as both reagents, in this case an amine and $\mathrm{CO}_{2}$, are dissolved in water before starting the reaction in a well mixed liquid solution. Therefore, the results of this direct method correspond to the intrinsic homogeneous reaction rate in an aqueous solution and are more accurate than those received using indirect techniques. Another important advantage is that small amounts of reactants can be used.

The most common detection methods to follow the kinetics are absorbance or fluorescence spectrometry. Many fast reactions involving ions do not result in measurable changes in absorbance or fluorescence but exhibit a change in conductivity as the reaction proceeds. This is the case of $\mathrm{CO}_{2}$ /amine/water systems where conductivity detection is typically used to monitor the reaction progress [17-21].

In stopped-flow experiments, two or more reactants are expelled from a set of syringes which are driven pneumatically or by stepping motors. The reactant solutions meet in a mixer where the reaction is initiated. The fresh reaction mixture is rapidly transferred into an observation cell while the previous content of the cell is flushed out. Then the liquid flow is stopped by a stopping syringe or hard stop valve at the exit of the cell [22]. The time required for the reactants to flow from the final point of mixing to the observation cell is referred to as a dead time. Commercial instruments can routinely reach dead times of a few milliseconds. The composition of the reaction mixture is monitored by recording the conductivity signal as a function of time. The most common mixing options for stopped-flow include single mixing and multi mixing where more than two solutions are mixed together. Similarly as in the heterogeneous experiments, the homogenous kinetic studies are also most commonly carried out under pseudo first order conditions when one reactant (an amine) is greatly in excess over the other reactant $\left(\mathrm{CO}_{2}\right)$. 


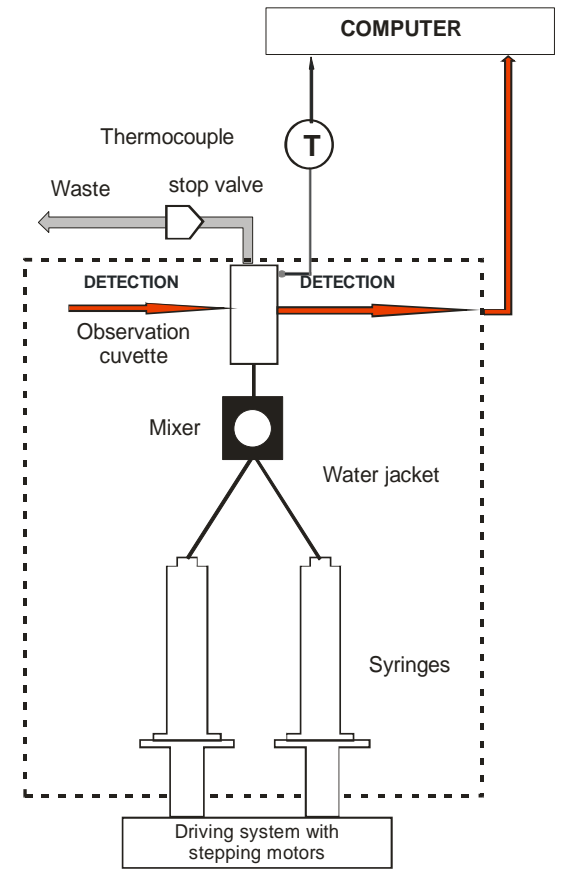

Fig. 6. Schematic of the stopped-flow apparatus (SFM-20, Bio-Logic SAS)

The experimental technique considered in our former study for the determination of homogeneous kinetics between $\mathrm{CO}_{2}$ and aqueous amine solutions is a SFM-20 stopped-flow system (Bio-Logic SAS), designed for single mixing rapid-kinetics applications. The SFM-20 module is connected with MCS-200 unit allowing conductivity measurements. The whole set-up is schematically illustrated in Figure 6. Details of the experimental conditions and procedure are described in my previous papers [20,21] and therefore only a brief description of the applied methodology will be given here. In a typical run, one syringe contained freshly saturated solution of $\mathrm{CO}_{2}$, which was prepared by dissolving a gas in water in a separate reactor under certain pressure. The other syringe contained an aqueous amine solution. Owing to the independent control of each syringe it was possible to make variable reagents mixing ratios to ensure an appropriate ratio of amine concentration to $\mathrm{CO}_{2}$ concentration after pushing into a mixer. An amine is typically used in excess and the amine to $\mathrm{CO}_{2}$ concentration ratio should be at least 15 in order to fulfill the pseudo first order regime with respect to $\mathrm{CO}_{2}$. During the process, the conductivity of reactants mixture increases, as the ionic products are formed. The averaged conductivity traces which are measured as a function of time are then fitted to the following exponential equation corresponding to a first-order kinetic equation [23]:

$$
\kappa=A_{S} \cdot \exp \left(-k_{o v} t\right)+\kappa_{\infty}
$$

where $\kappa$ is the specific conductance of the reaction mixture at time $t, \kappa_{\infty}$ is the constant value of the signal at the end of the reaction which is referred to as a baseline, $A_{S}$ denotes an amplitude of the signal. The kinetic equation (19) expressed in terms of conductance that is 
proportional to the concentration of ionic products is commonly used to analyze the first-order kinetic traces in a stopped-flow apparatus with a conductivity detection. It should be noted, however, that this equation is valid for diluted electrolyte solutions. Only in this case, the conductance of the specific ion is a linear function of its concentration. The overall rate constant $k_{o v}$ is obtained from a nonlinear least squares fit of Eq. (19) to the experimental data. A typical result of the stopped-flow experiment following the kinetics of $\mathrm{CO}_{2}$ reaction in aqueous MDEA solution is presented in Figure 7. In this case, the interpretation of the experimental data by a single, pseudo first order kinetics is justified in the narrowed time range, which was explained elsewhere [21].

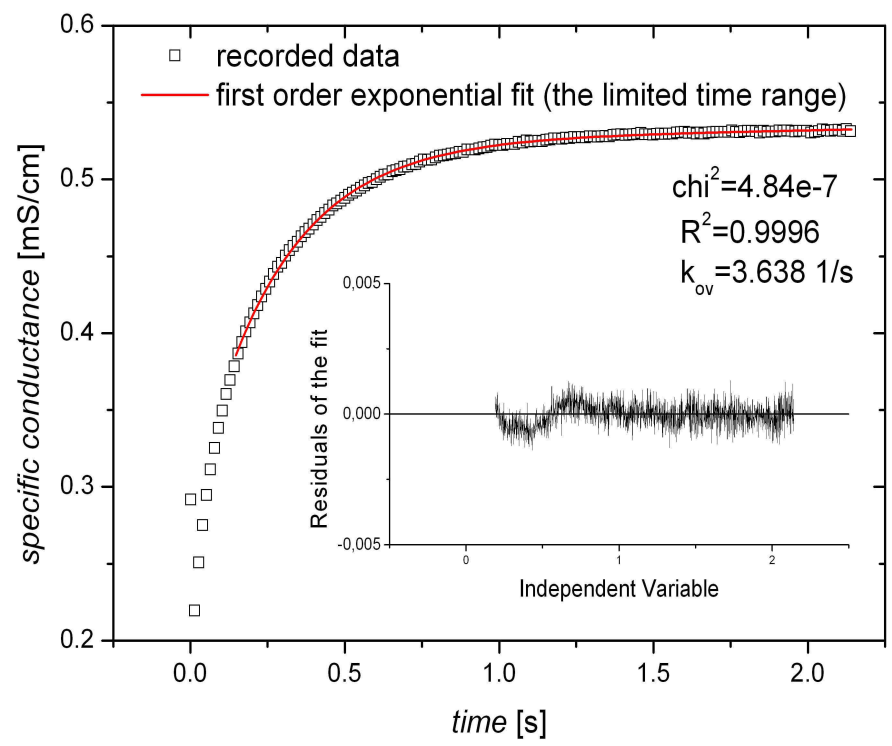

Fig. 7. A typical result of the stopped-flow experiment following the kinetics of $\mathrm{CO}_{2}$ reaction in aqueous MDEA solution $\left(\mathrm{T}=293.15 \mathrm{~K},[\mathrm{MDEA}]=0.8 \mathrm{kmol} / \mathrm{m}^{3}\right)$ - an example of data treatment $[21]$

A significant limitation of the stopped-flow technique is the possibility of following processes with the overall kinetic rate constant $k_{o v}$ of the order of some hundred reciprocal seconds depending on the dead time of a certain instrument. In the best case, monitoring the reaction progress with an observed rate constant close to $1000 \mathrm{~s}^{-1}$ is possible [22]. It means that the concentration of both reagents should be carefully selected to monitor the progress of a chemical reaction in the time much longer than the dead time. This fact imposes the necessity of performing experiments at low amine concentrations that are required to maintain sufficiently small $k_{o v}$. For fast reacting amines such as piperazine (PZ) and aminoethylaminoethanol (AEEA), fulfilling these conditions requires the use of amine concentrations smaller than $30 \mathrm{~mol} / \mathrm{m}^{3}$ and subsequently lower concentrations of $\mathrm{CO}_{2}$. For such conditions the amplitude of the corresponding conductivity of the reaction mixture is very small and comparable with signal to noise ratios, so the determination of kinetics in this range is unreasonable. It should be noted, however, that all results on the kinetics of 
$\mathrm{CO}_{2}$ reaction with alkanolamines reported in the literature which were studied by the use of stopped-flow technique with conductivity detection are restricted to the simple, pseudo first order analysis of experimental data.

When the reaction rate is too fast to allow measurements under pseudo first order regime, the rate constants can be determined under second order conditions. Therefore, it is necessary to determine the initial concentrations of both reagents accurately. However, the determination of a second order rate constant is not as simple and straightforward as in the case of pseudo first order approach because the variation of conductivity during the course of the reaction cannot be described by a single exponential function. A special treatment of the experimental curves must be considered to fit the individual kinetic model according to the given reaction stoichiometry.

For the experiments with dissolved $\mathrm{CO}_{2}$, bubble formation is very likely to occur especially when the $\mathrm{CO}_{2}$ concentration is larger than a quarter of its saturation value. Any kind of artifact may then happen which affects the shape or amplitude of the measured signal vs time. The possibility of occurrence of these effects when large $\mathrm{CO}_{2}$ concentrations are employed is another likely drawback of the homogeneous technique applied to study the intrinsic chemical reaction rate in gas-liquid systems. Furthermore, the air bubbles present in an amine solution, observed in the drive syringes before triggering, produce meaningless data.

\section{Example of analyzing the absorption experiments - reaction of $\mathrm{CO}_{2}$ with aqueous solutions of MDEA}

Methyldiethanolamine is the most popular tertiary amine used for $\mathrm{CO}_{2}$ removal in an industrial scale. The main advantages of MDEA over the extensively used monoethanolamine are its relatively high capacity, small enthalpy of the reaction with $\mathrm{CO}_{2}$ and low vapor pressure. Other worthy properties of MDEA include higher resistance to degradation and fewer corrosion problems compared with MEA. MDEA has very low reactivity with respect to $\mathrm{CO}_{2}$ due to its tertiary amine characteristics. The $\mathrm{CO}_{2}$ absorption rates in tertiary amines can be enhanced by the addition of small amounts of primary or secondary amines.

There is general agreement that tertiary amines act as catalysts for $\mathrm{CO}_{2}$ hydrolysis reaction according to [15]:

$$
\mathrm{CO}_{2}+\mathrm{R}_{1} \mathrm{R}_{2} \mathrm{R}_{3} \mathrm{~N}+\mathrm{H}_{2} \mathrm{O} \stackrel{k_{2}, K_{1}}{\longleftrightarrow} \mathrm{R}_{1} \mathrm{R}_{2} \mathrm{R}_{3} \mathrm{NH}^{+}+\mathrm{HCO}_{3}^{-}
$$

In accordance with the convention used in the literature, MDEA is represented as $\mathrm{R}_{1} \mathrm{R}_{2} \mathrm{R}_{3} \mathrm{~N}$, where $\mathrm{R}_{1}=\mathrm{R}_{2}=\mathrm{CH}_{2} \mathrm{CH}_{2} \mathrm{OH}$ and $\mathrm{R}_{3}=\mathrm{CH}_{3}$. The following reactions also occur in aqueous solutions:

$$
\begin{gathered}
\mathrm{CO}_{2}+\mathrm{OH}^{-} \stackrel{k_{O H}, K_{2}}{\longleftrightarrow} \mathrm{HCO}_{3}^{-} \\
\mathrm{HCO}_{3}^{-}+\mathrm{OH}^{-} \stackrel{K_{3}}{\longleftrightarrow} \mathrm{CO}_{3}^{2-}+\mathrm{H}_{2} \mathrm{O} \\
\mathrm{R}_{1} \mathrm{R}_{2} \mathrm{R}_{3} \mathrm{NH}^{+}+\mathrm{OH}^{-} \stackrel{K_{4}}{\longleftrightarrow} \mathrm{R}_{1} \mathrm{R}_{2} \mathrm{R}_{3} \mathrm{~N}+\mathrm{H}_{2} \mathrm{O} \\
2 \mathrm{H}_{2} \mathrm{O} \stackrel{K_{5}}{\longleftrightarrow} \mathrm{OH}^{-}+\mathrm{H}_{3} \mathrm{O}^{+}
\end{gathered}
$$


Reactions (20) and (21) take place in parallel with the finite rates which are described by the forward second order rate constants $k_{2}$ and $k_{O H}$ and equilibrium constants $K_{1}$ and $K_{2}$. Reactions (22)-(24) are instantaneous as they involve only a proton transfer.

The kinetics of the reaction of $\mathrm{CO}_{2}$ with aqueous MDEA was widely investigated [12, 15, 21, 24-29] using several experimental techniques. Although the kinetic mechanisms for tertiary amines are much simpler than for primary or secondary amines, for which carbamate formation has to be considered, discrepancies have appeared in the literature concerning the reported rate constants which are summarized in Table 2. A relatively big difference in the forward rate constant $k_{2}$ is partly affected by the method of analyzing the kinetic data and assumptions involved, especially these regarding the contribution of reaction (21) to the observed reaction rate. Some of these discrepancies in the reported rate constants may also be attributed to the different experimental techniques and their limitations as well as the inconsistency of the physical data such as $\mathrm{CO}_{2}$ solubility and diffusivity used to interpret the absorption rate data.

Table 2

Selected literature data on the reaction between $\mathrm{CO}_{2}$ and aqueous MDEA

\begin{tabular}{|c|c|c|c|c|c|}
\hline \multirow{2}{*}{ Reference } & MDEA conc. & \multicolumn{3}{|c|}{$\boldsymbol{k}_{\mathbf{2}}\left[\mathbf{m}^{\mathbf{3}} \mathbf{~ k m o l}^{\mathbf{- 1}} \mathbf{s}^{\mathbf{- 1}}\right]$} & \multirow{2}{*}{ Experimental technique } \\
\cline { 3 - 5 } & {$\left[\mathbf{k m o l} / \mathbf{m}^{\mathbf{3}}\right]$} & $\mathbf{2 9 3 . 1 5} \mathbf{~ K}$ & $\mathbf{3 1 3 . 1 5} \mathbf{~ K}$ & $\mathbf{3 3 3 . 1 5} \mathbf{~ K}$ & stopped-flow \\
& $0.25 \div 0.875$ & 5.09 & $20.7^{*}$ & - & laminar jet \\
{$[21]$} & $0 \div 1.7$ & 1.46 & $9.6^{*}$ & - & hemispherical contactor \\
{$[24]$} & $0.4 \div 3.2$ & 5.15 & 18.2 & 55.3 & wetted wall column \\
{$[26]$} & $1 \div 2.5$ & 4.01 & 13.0 & - & stirred cell \\
{$[12]$} & $0.2 \div 3$ & 3.78 & 13.2 & 40.0 & stirred cell \\
{$[27]$} & $0.83 \div 2.5$ & 5.70 & - & - & stirred cell \\
{$[28]$} & $0.83 \div 4.38$ & 3.80 & 12.5 & 35.6 & wetted-sphere absorber \\
\hline 29$]$ & $0.83 \div 2.5$ & 4.79 & 13.0 & - & \\
\hline
\end{tabular}

*) extrapolated data

In the following section, some of our earlier experiments reported previously in [15] will be further analyzed and reinterpreted. As previously indicated, the simplified kinetic model can be applied which assumes that the main reaction (20) of $\mathrm{CO}_{2}$ with MDEA is irreversible and the contribution of reaction (21) to the overall absorption rate is negligible. The use of this assumption was supported by findings of the detailed mathematical model of the system under consideration [30]. The conditions for the absorption of $\mathrm{CO}_{2}$ in MDEA solutions were selected in such a way as to ensure that the absorption occurs in the fast pseudo first order reaction regime. Under these assumptions, the total rate of $\mathrm{CO}_{2}$ reaction in the aqueous solution of MDEA may be expressed as:

$$
r_{o v}=k_{2}[\mathrm{MDEA}]\left[\mathrm{CO}_{2}\right]=k_{o v}\left[\mathrm{CO}_{2}\right]
$$

The overall reaction kinetic constant $k_{o v}$ is defined as:

$$
k_{o v}=k_{2}[\mathrm{MDEA}]_{0}
$$

where $[\mathrm{MDEA}]_{0}$ states for the initial MDEA concentration in the solution.

The absorption of $\mathrm{CO}_{2}$ into MDEA solutions was studied using the stirred cell setup similar to that illustrated in Figure 4. The process was realized batchwise with respect to both phases and the absorption rate was calculated from the pressure decrease according to Eq. (18). In the range of stirring speed of $100 \div 180 \mathrm{~min}^{-1}$, the absorption rate was found to 
be independent of the stirring speed indicating a pseudo first order regime. Thus, all experimental runs were performed at a constant stirring speed of $120 \mathrm{~min}^{-1}$. Under such conditions, the gas liquid interface was flat and could be easily estimated. The maximum $\mathrm{CO}_{2}$ loading in the analyzed pressure range varied between 0.002 and $0.004 \mathrm{~mol} \mathrm{CO} / \mathrm{mol}$ MDEA corresponding to MDEA conversions lower than $1 \%$. It is justified to assume that the influence of reverse reactions can be neglected for the experimental conditions used in this work. The bulk $\mathrm{CO}_{2}$ concentration at the initial state of the batch absorption run is equal to zero as the aqueous MDEA solutions used in the absorption experiments were not initially loaded with $\mathrm{CO}_{2}$. Thus, the specific rate of mass transfer of $\mathrm{CO}_{2}$ can be interpreted by Eq. (9).

Kinetics data of $\mathrm{CO}_{2}$ absorption into aqueous MDEA [15] and calculated values of $E_{\text {inf }}$ and experimental $E_{A}$

\begin{tabular}{|c|c|c|c|c|c|c|}
\hline Temperature & {$[\text { MDEA }]_{0}$} & $k_{A L} \cdot 10^{5}$ & $p_{A}$ & $N_{A L}{ }^{*} \cdot 10^{6}$ & $E_{\text {inf }}$ & $E_{A, \exp }$ \\
\hline$[\mathrm{K}]$ & {$\left[\mathrm{kmol} / \mathrm{m}^{3}\right]$} & {$[\mathrm{m} / \mathrm{s}]$} & [kPa] & {$\left[\mathrm{kmol} /\left(\mathrm{m}^{2} \mathrm{~s}\right)\right]$} & - & - \\
\hline \multirow[t]{8}{*}{293.15} & \multirow[t]{8}{*}{0.845} & \multirow[t]{8}{*}{2.02} & 108.3 & 2.32 & 10.4 & 2.87 \\
\hline & & & 97.0 & 2.22 & 11.5 & 3.07 \\
\hline & & & 93.0 & 2.06 & 12.0 & 2.97 \\
\hline & & & 86.0 & 1.87 & 12.9 & 2.92 \\
\hline & & & 67.5 & 1.53 & 16.1 & 3.04 \\
\hline & & & 42.5 & 0.99 & 25.1 & 3.13 \\
\hline & & & 33.8 & 0.93 & 31.3 & 3.69 \\
\hline & & & 34.9 & 1.05 & 30.4 & 4.04 \\
\hline \multirow[t]{4}{*}{293.15} & \multirow[t]{4}{*}{1.706} & \multirow[t]{4}{*}{1.43} & 67.4 & 1.62 & 36.4 & 4.89 \\
\hline & & & 59.0 & 1.55 & 41.4 & 5.35 \\
\hline & & & 52.3 & 1.38 & 46.6 & 5.37 \\
\hline & & & 46.8 & 1.23 & 51.9 & 5.35 \\
\hline \multirow[t]{5}{*}{313.15} & \multirow[t]{5}{*}{0.840} & \multirow[t]{5}{*}{3.19} & 77.1 & 2.66 & 22.3 & 4.79 \\
\hline & & & 58.2 & 2.21 & 29.3 & 5.27 \\
\hline & & & 55.6 & 1.93 & 30.6 & 4.82 \\
\hline & & & 43.9 & 1.68 & 38.5 & 5.31 \\
\hline & & & 36.4 & 1.39 & 46.3 & 5.30 \\
\hline \multirow[t]{5}{*}{313.15} & \multirow[t]{5}{*}{1.694} & \multirow[t]{5}{*}{2.28} & 88.0 & 3.61 & 43.9 & 5.98 \\
\hline & & & 57.8 & 2.19 & 66.4 & 5.52 \\
\hline & & & 37.8 & 1.60 & 101.1 & 6.17 \\
\hline & & & 35.9 & 1.66 & 106.4 & 6.74 \\
\hline & & & 34.7 & 1.40 & 110.1 & 5.88 \\
\hline \multirow[t]{4}{*}{333.15} & \multirow[t]{4}{*}{0.834} & \multirow[t]{4}{*}{5.07} & 51.1 & 2.68 & 24.3 & 6.62 \\
\hline & & & 46.2 & 2.24 & 26.8 & 6.12 \\
\hline & & & 42.7 & 2.11 & 29.0 & 6.24 \\
\hline & & & 33.9 & 1.77 & 36.3 & 6.59 \\
\hline \multirow[t]{4}{*}{333.15} & \multirow[t]{4}{*}{1.68} & \multirow[t]{4}{*}{3.91} & 52.3 & 3.11 & 39.2 & 10.24 \\
\hline & & & 48.2 & 2.96 & 42.5 & 10.57 \\
\hline & & & 43.7 & 2.49 & 46.8 & 9.81 \\
\hline & & & 26.0 & 1.82 & 78.1 & 12.05 \\
\hline
\end{tabular}




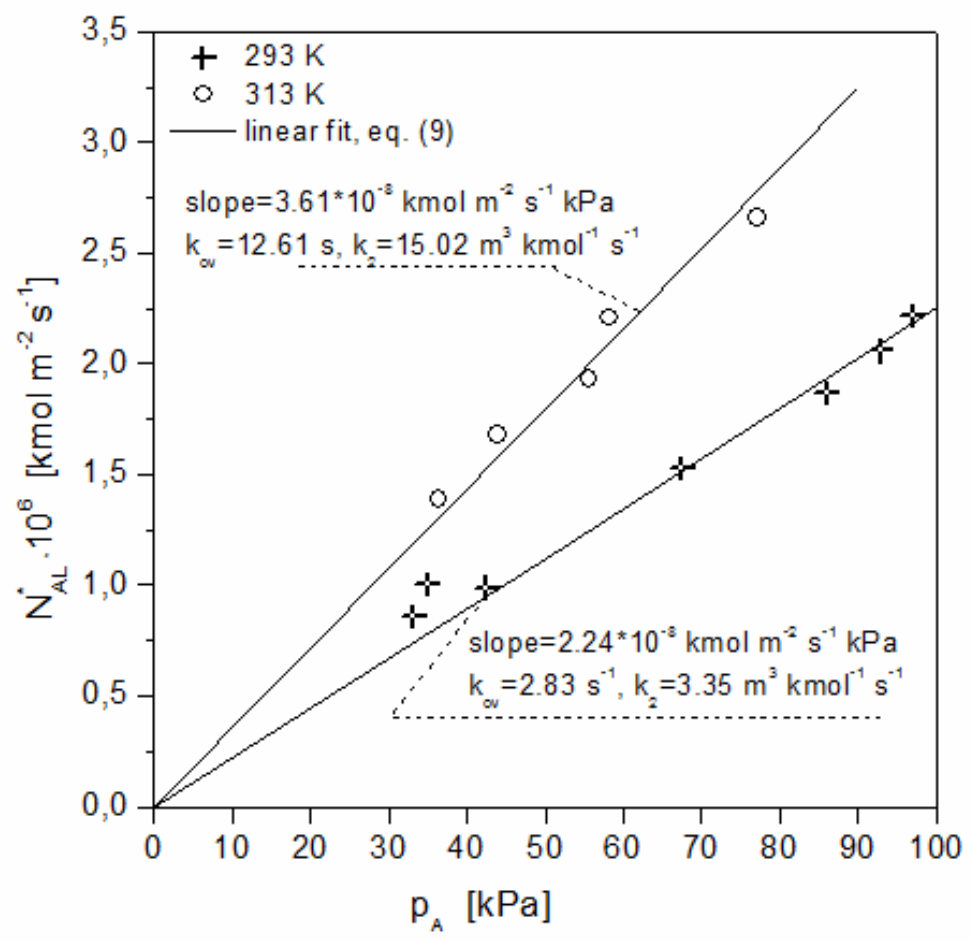

Fig. 8. Example of data treatment assuming pseudo first order regime. Experimental data at $[\mathrm{MDEA}]_{0}=0.84 \mathrm{kmol} / \mathrm{m}^{3}$

The experimentally determined $\mathrm{CO}_{2}$ absorption rates along with the relevant operation conditions are reported in Table 3 . Additionally, the corresponding values of $E_{\text {inf }}$ were calculated. Plotting experimental $N_{A L}^{*}$ as a function of $p_{A}$ gave a straight line passing through the origin at a given temperature and amine concentration and enabled calculation of the overall and second order kinetic rate constants as shown in Figure 8. All physicochemical properties needed for extracting $k_{o v}$ from the slope are summarized in the previous paper [15]. The results of $k_{2}$ were subsequently fitted to the following Arrhenius equation:

$$
k_{2}\left[\mathrm{~m}^{3} \mathrm{kmol}^{-1} \mathrm{~s}^{-1}\right]=2.07 \times 10^{9} \exp (-5912.7 / T)
$$

Finally, at this point the pseudo first order regime can be validated by checking if the criterion (6) is fulfilled. The $k_{2}$ values calculated from Eq. (27) for three temperatures studied and the respective Ha numbers are given in Table 4. These data show that in all

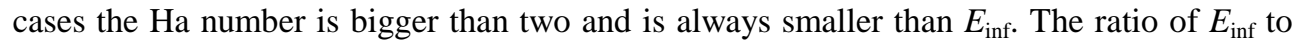
$\mathrm{Ha}$ is between 3 and 19. According to the findings of other investigators [7], pseudo first order behavior is, however, only really ensured at $E_{\text {inf }}$ to Ha ratios of at least the factor of 10. Therefore, with the factor smaller than 10 it might be necessary not only to interpret the results according to Eq. (9) (pseudo first order regime) but rather with the help of Eq. (11) (fast intermediate regime). 
Experimental results of $\mathrm{k}_{2}$ determination according to the interpretation methods applied

\begin{tabular}{|c|c|c|c|c|c|}
\hline \multirow[t]{2}{*}{ Temperature } & \multirow[t]{2}{*}[\text{MDEA}]{$_{0}$} & \multicolumn{2}{|c|}{$\begin{array}{l}\text { Pseudo first order } \\
\text { regime [15] }\end{array}$} & \multicolumn{2}{|c|}{$\begin{array}{c}\text { Fast intermediate } \\
\text { regime-global analysis }\end{array}$} \\
\hline & & $k_{2}$ from Eq. (27) & $\mathbf{H a}$ & $k_{2}$ & Ha \\
\hline$[\mathrm{K}]$ & {$\left[\mathrm{kmol} / \mathrm{m}^{3}\right]$} & {$\left[\mathrm{m}^{3} /(\mathrm{kmol} \mathrm{s})\right]$} & - & {$\left[\mathrm{m}^{3} /(\mathrm{kmol} \mathrm{s})\right]$} & - \\
\hline 293.15 & 0.85 & \multirow[t]{2}{*}{3.6} & 3.08 & \multirow[t]{2}{*}{4.13} & 3.30 \\
\hline 293.15 & 1.71 & & 5.27 & & 5.64 \\
\hline 313.15 & 0.84 & \multirow[t]{2}{*}{13.06} & 4.68 & \multirow[t]{2}{*}{14.28} & 4.89 \\
\hline 313.15 & 1.69 & & 5.67 & & 5.93 \\
\hline 333.15 & 0.83 & \multirow[t]{2}{*}{40.57} & 6.58 & \multirow[t]{2}{*}{42.50} & 6.74 \\
\hline 333.15 & 1.68 & & 10.74 & & 10.98 \\
\hline \multicolumn{2}{|c|}{$S S E=\sum\left(E_{A, \exp }-E_{A, \text { calc }}\right)^{2}$} & \multicolumn{2}{|l|}{7.441} & \multicolumn{2}{|c|}{5.934} \\
\hline
\end{tabular}

For the aim of further analysis, the experimental enhancement factors were calculated based on the measured $N_{A L}^{*}$ for all operating conditions according to:

$$
E_{A, \exp }=\frac{N_{A L}^{*}}{k_{A L} c_{A L}^{*}}
$$

Then Eq. (11) describing the dependence of the enhancement factor on both Ha and $E_{\text {inf }}$ was fitted to the experimental results of $E_{A \text {,exp }}$ for all temperatures and concentrations considered, in order to obtain the kinetic parameters. In Eq. (11), the kinetic rate constant was expressed by Arrhenius law equation with an activation energy and preexponential factor as fitting parameters. These parameters were determined by minimizing the sum of square residues (SSE) defined by the following formula:

$$
S S E=\sum_{i=1}^{n}\left(E_{\exp , i}-E_{c a l, i}\right)^{2}
$$

The resulting expression for the second order rate constant has the following form:

$$
k_{2}\left[\mathrm{~m}^{3} \mathrm{kmol}^{-1} \mathrm{~s}^{-1}\right]=1.11 \times 10^{9} \exp (-5690 / T)
$$

Table 4 gives the values of kinetic parameters that minimize the quality index for the Wellek approximate solution used for data interpretation. The corresponding Ha numbers are also listed. The value of SSE quality index showed good agreement between the experimental data and corresponding fit. It is worth to note that it is smaller than the one calculated for the previous results interpreted with the assumption of pseudo first order regime [15], where the data were analyzed separately at a given temperature in contrast to the global analysis applied for the intermediate regime. As expected, the determination of kinetics using Eq. (11) valid for the intermediate regime yields larger second order kinetic rate constants, but the discrepancy between both sets of results is not significant. The maximum relative difference does not exceed $13 \%$ at $293 \mathrm{~K}$. It seems that for some experiments the deviation from the pseudo first order regime occurs as at high $\mathrm{CO}_{2}$ partial pressure and low concentration of amine compared to $\mathrm{CO}_{2}$ flux, partial depletion of amine in the liquid film can take place. In addition to this, low physical mass transfer coefficient $k_{A L}$ limits the transport of amine from the bulk to the interface and products from the interface to the bulk. 
To sum up, the above analysis has provided two methods to interpret the experimentally obtained absorption rates. These various interpretation techniques can lead to different kinetic rate constants. Eq. (11) fits the data very well, a bit better than Eq. (9), which corresponds to the pseudo first order regime. The results obtained with the Wellek relation are considered to be the most accurate, since the pseudo first order criteria are likely not to be fully satisfied for some experiments. However, the difference between both sets of $k_{2}$ is not significant and does not exceed a few per cent.

It should be noted finally that derivation of the kinetic rate constants from the measured absorption rates introduces some uncertainties with respect the physicochemical data used for data interpretation. The effect of possible errors in the values of physical property parameters on predicted kinetic rate constants were generated by introducing $+10 \%$ deviation in Henry's constant of $\mathrm{CO}_{2}$ and $\mathrm{CO}_{2}$ diffusivity in the amine solution calculated from various correlations available in the literature. The data were subsequently analyzed globally according to Eq. (11). The results show that a $10 \%$ increase in He causes the values of $k_{2}$ to increase by about $20 \%$. The predicted $k_{2}$ are less sensitive to $\mathrm{CO}_{2}$ diffusivity as the increase in $D_{A L}$ by $10 \%$ resulted in $k_{2}$ smaller by about $8 \%$. The calculations indicate that accurate values of Henry's constant and $\mathrm{CO}_{2}$ diffusivity in amine solutions are very important for the determination of reaction kinetics as these parameters have a considerable effect on the predicted rate constants.

New data for the second order rate constants for the $\mathrm{CO}_{2}$ reaction with MDEA were found to be in good agreement with published values. The values of $k_{2}$ obtained in this work are very close to those derived by Rinker et al [30] over the whole temperature range. The $k_{2}$ values of Jamal et al [25] are slightly higher than the present ones. The observed discrepancies may come from the different absorption apparatus and the assumptions involved while interpreting the observed overall kinetic rate constant. It should be noted, however, that the values obtained by the stopped-flow method with conductivity detection [21] are close to the results of Jamal et al [25] and a bit higher than the other ones determined with the use of heterogeneous techniques. It is worth to emphasize that it is not possible to compare our former results obtained by the use of the stopped-flow technique [21] with other analogous studies because no one made such measurements.

\section{Conclusions}

In this paper a brief overview of the determination methods of reaction kinetics in gas-liquid systems with a special emphasis on $\mathrm{CO}_{2}$ absorption in aqueous alkanolamine solutions is presented. Both homogeneous and heterogeneous experimental techniques were reviewed. The main features of the stirred cell reactor and the experimental procedure with the corresponding theoretical background needed for the interpretation of results are presented in more detail. A concise description of a conductometric stopped-flow apparatus is outlined with the respective advantages and disadvantages in relation to measuring the kinetics of $\mathrm{CO}_{2}$ reaction with amine solutions.

The case of $\mathrm{CO}_{2}$ reaction in the aqueous solutions of MDEA is discussed as an illustrative example of the use of both techniques including a stirred cell apparatus and stopped-flow method for the determination of kinetics. The results of our previous experimental studies conducted using a stirred cell [15] are reviewed and reinterpreted. Two approaches were used to obtain the second order rate constants from the measured 
absorption rates. The former analysis was based on the assumption of pseudo first order regime and the data were analyzed separately at a given temperature. Since the conditions for fast pseudo first order regime were apparently not fulfilled for some experiments, the Wellek equation for the enhancement factor was applied in order to identify the kinetic parameters and all data were analyzed globally. As expected, the determination of the kinetics using the Wellek relation which is valid for the intermediate regime yields slightly larger second order kinetic rate constants. However, the difference between both sets of $k_{2}$ is not significant and does not exceed $13 \%$ in the worst case. The derivation of the kinetic rate constants from the measured absorption rates is very sensitive to uncertainties with respect to the physicochemical properties used for data interpretation. The sensitivity analyses indicate that accurate values of Henry's constant and $\mathrm{CO}_{2}$ diffusivity in amine solutions are very important for the determination of reaction kinetics as these parameters have a considerable effect on the predicted rate constants.

To sum up, it was demonstrated that different measurement techniques and methods of analyzing the experimental data can substantially influence the determination of the rate constant. The $k_{2}$ values obtained directly by the stopped-flow method with conductivity detection published previously [21] are slightly higher than the ones determined indirectly with the use of the heterogeneous technique.

\section{Nomenclature}

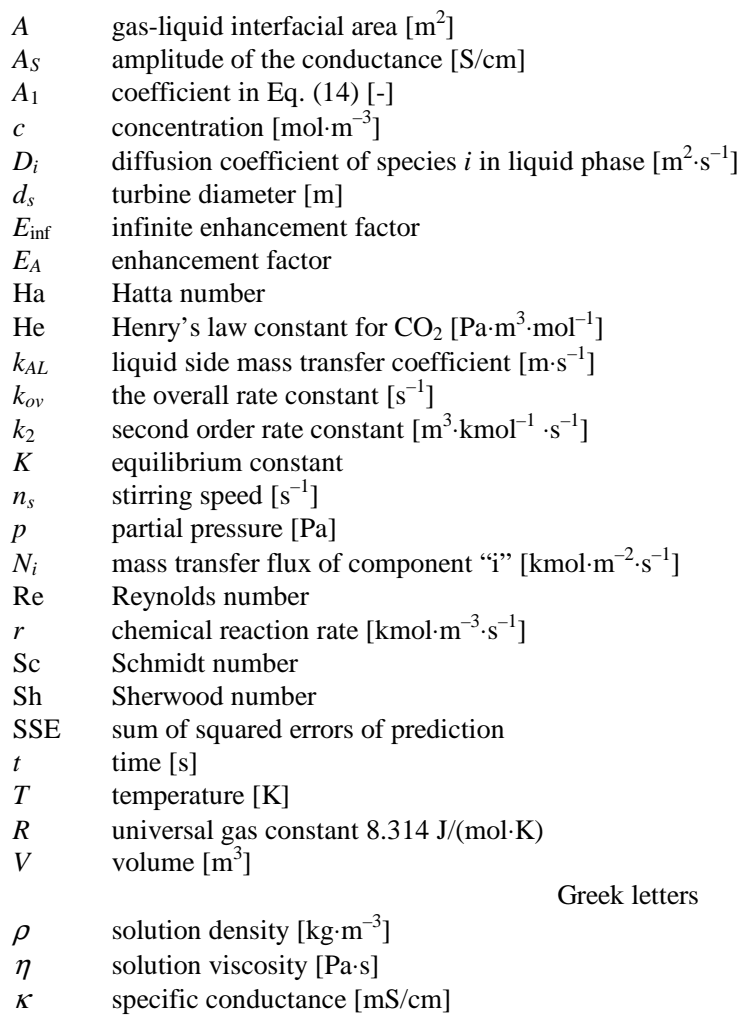


Subscripts

gas component

liquid component

gas phase

liquid phase

refers to liquid bulk

gas-liquid interface

initial state

MDEA methyldiethanoloamine

\section{References}

[1] Vaidya PD, Kenig E.Y. $\mathrm{CO}_{2}$-alkanolamine reaction kinetics: A review of recent studies. Chem Eng Technol. 2007;30(11):1467-1474. DOI: 10.1002/ceat.200700268.

[2] Shah YT. Gas-Liquid-Solid Reactor Design. McGraw-Hill; 1979.

[3] Vaidya PD, Kenig EY. Gas-liquid reaction kinetics: a review of determination methods. Chem Eng Comm. 2007;194(12):1543-1565. DOI: 10.1080/00986440701518314.

[4] Aboudheir A, Tontiwachwuthikul P, Chakma A, Idem R. Kinetics of reactive absorption of carbon dioxide in high CO2-loaded concentrated aqueous monoethanolamine solutions. Chem Eng Sci. 2003;58(23):5195-5210. DOI: 10.1016/j.ces.2003.08.014.

[5] Zarzycki R, Chacuk A. Absorption: Fundamentals and Applications. Oxford: Pergamon Press; 1993.

[6] van Swaaij WPM, Versteeg GF. Mass transfer accompanied with complex reversible chemical reactions in gas-liquid systems: an overview. Chem Eng Sci. 1992;47:3181-3195. DOI: 10.1016/0009-2509(92)85028A.

[7] Derks PWJ, Kleingeld T, van Aken C, Hogendoorn JA, Versteeg GF. Kinetics of absorption of carbon dioxide in aqueous piperazine solutions. Chem Eng Sci. 2006;61(20):6837-6854. DOI:10.1016/j.ces.2006.07.009.

[8] Kierzkowska-Pawlak H, Zarzycki R. Solubility of carbon dioxide and nitrous oxide in water + methyldiethanolamine and ethanol + methyldiethanolamine solutions. $\mathrm{J}$ Chem Eng Data. 2002;47(6):1506-1509. DOI: 10.1021/je020093v.

[9] Versteeg GF, van Dijck LAJ, van Swaaij WPM. On the kinetics between $\mathrm{CO}_{2}$ and alkanolamines both in aqueous and non-aqueous solutions. An overview. Chem Eng Comm. 1996;144:113-158. DOI: $10.1080 / 00986449608936450$.

[10] Jamal A, Meisen A, Jim Lim C. Kinetics of carbon dioxide absorption and desorption in aqueous alkanolamine solutions using a novel hemispherical contactor. I. Experimental apparatus and mathematical modeling. Chem Eng Sci. 2006;61:6571-6589. DOI: 10.1016/j.ces.2006.04.046.

[11] Portugala AF, Derks PWJ, Versteeg GF, Magalhaesa FD, Mendesa A. Characterization of potassium glycinate for carbon dioxide absorption purposes. Chem Eng Sci. 2007;62:6534-6547. DOI:10.1016/j.ces.2007.07.068.

[12] Littel RJ, van Swaaij WPM, Versteeg GF. Kinetics of carbon dioxide with tertiary amines in aqueous solutions. AIChE J. 1990;36:1633-1640. DOI: 10.1002/aic.690361103.

[13] Zhang X, Zhang C-F, Liu Y. Kinetics of absorption of $\mathrm{CO}_{2}$ into aqueous solution of MDEA blended with DEA. Ind Eng Chem Res. 2002;41(5):1135-1141. DOI: 10.1021/ie010605j.

[14] Vaidya PD, Kenig EY. A study on $\mathrm{CO}_{2}$ absorption kinetics by aqueous solutions of N.N-diethylethanolamine and N-ethylethanolamine. Chem Eng Tech. 2009;32(4):556-563. DOI: $10.1002 /$ ceat.200800573.

[15] Kierzkowska-Pawlak H, Chacuk A. Kinetics of carbon dioxide absorption into aqueous MDEA solutions. Ecol Chem Eng S. 2010;17(4):463-475.

[16] Littel RJ, Versteeg GF, van Swaaij WPM. Physical absorption into non-aqueous solutions in a stirred cell reactor. Chem Eng Sci. 1991;46(12):3308-3313. DOI: 10.1016/0009-2509(91)85036-W.

[17] Li J, Henni A, Tontiwachwuthikul $\mathrm{P}$. Reaction kinetics of $\mathrm{CO}_{2}$ in aqueous ethylenediamine, ethylethanolamine, and diethylmonoethanolamine solutions in the temperature range of 298-313 K, using the stopped-flow technique. Ind. Eng. Chem. Res. 2007;46:4426-4434. DOI: 10.1021/ie0614982.

[18] Ali SH, Merchant SQ, Fahim MA. Reaction kinetics of some secondary alkanolamines with carbon dioxide in aqueous solutions by stopped-flow technique. Sep Purif Technol. 2002;27:121-126. DOI: $10.1016 / \mathrm{S} 1383-5866(01) 00206-4$. 
[19] Henni A, Li J, Tontiwachwuthikul P. Reaction kinetics of $\mathrm{CO}_{2}$ in aqueous 1-amino-2-propanol. 3-amino-1-propanol. and dimethylmonoethanolamine solutions in the temperature range of 298-313 K using the stopped-flow technique. Ind Eng Chem Res. 2008;47(7):2213-2220. DOI: dx.doi.org/10.1021/ie070587r.

[20] Siemieniec M, Kierzkowska-Pawlak $\mathrm{H}$, Chacuk A. Reaction kinetics of $\mathrm{CO}_{2}$ in aqueous diethanolamine solutions in the temperature range of $293 \div 313 \mathrm{~K}$ using the stopped-flow technique. Ecol Chem Eng S. 2012;19(1):55-66. DOI 10.2478/v10216-011-0006-y.

[21] Kierzkowska-Pawlak $\mathrm{H}$, Siemieniec $\mathrm{M}$, Chacuk A. Reaction kinetics of $\mathrm{CO}_{2}$ in aqueous methyldiethanolamine solutions using the stopped-flow technique. Chem Proc Eng. 2012;33(1):7-18. DOI: $10.2478 / \mathrm{v} 10176-012-0001-6$

[22] Wang. R-Y. Rapid Scan. Stopped-Flow Kinetics. In: Encyclopedia of Inorganic Chemistry. John Wiley \& Sons. Ltd; 2008. DOI: 10.1002/0470862106.ia326.

[23] Knipe AC, McLean D, Tranter NL. A fast response conductivity amplifier for chemical kinetics. J Phys E. 1974;7:586-590. DOI:10.1088/0022-3735/7/7/025.

[24] Haimour N, Bidarian A, Sandall OC. Kinetics of the reaction between carbon dioxide and methyldiethanolamine. Chem Eng Sci. 1987;42(6):1393-1398. DOI: 10.1016/0009-2509(87)85011-X.

[25] Jamal A, Meisen A, Jim Lim C. Kinetics of carbon dioxide absorption and desorption in aqueous alkanolamine solutions using a novel hemispherical contactor - II. Experimental results and parameter estimation. Chem Eng Sci. 2006;61(19):6590-6603. DOI: 10.1016/j.ces.2006.04.047.

[26] Ko J-J, Li M-H. Kinetics of absorption of carbon dioxide into solutions of N-methyldiethanolamine+water. Chem Eng Sci. 2000;55(19):4139-4147. DOI: 10.1016/S00092509(00)00079-8.

[27] Moniuk W, Pohorecki R. Absorpcja $\mathrm{CO}_{2}$ w wodnych roztworach N-metylodwuetanoloaminy. Inż Chem i Proces. 2000;21(1):183-197.

[28] Pani F, Gaunand A, Cadours R, Bouallou C, Richon D. Kinetics of absorption of $\mathrm{CO}_{2}$ in concentrated aqueous methyldiethanolamine solutions in the range $296 \mathrm{~K}$ to $343 \mathrm{~K}$. J Chem Eng Data. 1997;42(2):353-359. DOI: 10.1021/je960251g.

[29] Rinker EB, Ashour SS, Sandall OC. Kinetics and modeling of carbon dioxide absorption into aqueous solutions of N-methylodiethanolamine. Chem Eng Sci. 1995;50(5):755-768. DOI: 10.1016/00092509(94)00444-V.

[30] Kierzkowska-Pawlak $\mathrm{H}$, Chacuk A. Numerical simulation of $\mathrm{CO}_{2}$ absorption into aqueous MDEA solutions. Korean J Chem Eng. 2012;29(6): in press. DOI: 10.1007/s11814-011-0244-9.

\title{
PRZEGLĄD METOD WYZNACZANIA KINETYKI REAKCJI GAZ-CIECZ
}

\author{
Wydział Inżynierii Procesowej i Ochrony Środowiska, Politechnika Łódzka
}

\begin{abstract}
Abstrakt: Celem niniejszej pracy jest przegląd metod określania kinetyki reakcji gaz-ciecz ze szczególnym uwzględnieniem absorpcji $\mathrm{CO}_{2} \mathrm{w}$ wodnych roztworach alkanoloamin. Omówiono zarówno homofazowe, jak i heterofazowe techniki eksperymentalne wraz $\mathrm{z}$ podstawami teoretycznymi niezbędnymi do interpretacji wyników. Jako przykład zinterpretowano wyniki własnych badań absorpcji $\mathrm{CO}_{2}$ w wodnych roztworach metylodietanoloaminy. Wykazano, że różne techniki pomiarowe i metody analizy danych doświadczalnych mają wpływ na otrzymaną zależność stałej szybkości reakcji od temperatury.
\end{abstract}

Słowa kluczowe: kinetyka reakcji gaz-ciecz, reaktor z mieszadłem, technika zatrzymanego przepływu, czynnik przyspieszenia, absorpcja $\mathrm{CO}_{2}$, metylodietanoloamina 